\title{
Effect of Dihydropyridine Calcium-Channel Blocker on Adverse Aortic Events After Thoracic Endovascular Aortic Repair for Type B Aortic Dissection
}

\author{
Fan Yang \\ Guangdong Provincial People's Hospital \\ Lyufan Chen \\ Guangdong Provincial People's Hospital \\ Jitao Liu \\ Guangdong Provincial People's Hospital \\ Songyuan Luo \\ Guangdong Provincial People's Hospital \\ Caiyun He \\ Guangdong Provincial People's Hospital \\ Wentao Ma \\ Guangdong Provincial People's Hospital \\ Enmin Xie \\ Guangdong Provincial People's Hospital \\ Xinyue Yang \\ Guangdong Provincial People's Hospital \\ Hongke Zeng \\ Guangdong Provincial People's Hospital \\ Qingshan Geng \\ Guangdong Provincial People's Hospital \\ Jianfang Luo ( $\sim$ jianfangluo@sina.com ) \\ Guangdong Provincial People's Hospital
}

\section{Research Article}

Keywords: aortic dissection, thoracic endovascular aortic repair, medical therapy, outcome

Posted Date: September 17th, 2021

DOI: https://doi.org/10.21203/rs.3.rs-877422/v1

License: (9) (i) This work is licensed under a Creative Commons Attribution 4.0 International License. Read Full License 


\section{Abstract}

Objectives: This study aimed to evaluate the effect of dihydropyridine calcium-channel blocker (CCB) on adverse aortic events (AAE) in patients undergoing thoracic endovascular aortic repair (TEVAR) for type B aortic dissection (TBAD).

Methods: A retrospective study was conducted on patients undergoing TEVAR of TBAD from January 2010 to December 2017 in our center. Patients were divided into CCB group and non-CCB group according to the postoperative dihydropyridine CCB use. $A A E$ including aorta-relative mortality and reintervention, were compared between these two groups. Propensity score matching analysis was performed to avoid the potential effect of known confounders.

Results: Before matching, the study cohort comprised 548 patients, including 435 (79.4\%) and 113 (20.6\%) patients in the CCB and non-CCB groups, respectively. After matching, 101 patients in each group were eligible for the analysis. In the unmatched cohort, AAE occurred in $52(12.0 \%)$ and $29(25.7 \%)$ patients in the CCB and non-CCB groups, respectively $(P<0.001)$. In the matched cohort, AAE occurred in $8(7.9 \%)$ and $22(21.8 \%)$ patients in the CCB and non-CCB groups, respectively $(P=0.013)$. Log-rank test analysis revealed that the levels of freedom from AAE were significantly different between the 2 groups in both the unmatched and matched cohorts $(P<0.001$ and $P=0.007$, respectively). Multivariable analysis showed that CCB use (hazard ratio $0.50,95 \%$ confidence interval $0.32-0.80 ; P=0.003$ ) was associated with a lower AAE rate after adjustment for other variables, and was minimally changed after the propensity score matching ( $\mathrm{HR} 0.34,95 \% \mathrm{Cl} 0.15-0.75 ; \mathrm{P}=0.008)$.

Conclusions: Postoperative dihydropyridine CCB use is protective in patients undergoing TEVAR for acute and sub-acute TBAD.

\section{Backgrounds}

Management of type B aortic dissection (TBAD), a life-threatening cardiovascular disease with high mortality and morbidity, includes medical therapy, thoracic endovascular aortic repair (TEVAR) and surgery. ${ }^{1}$ Stable patients with TBAD are managed with medical therapy aimed at the reduction of shear stress on affected aortic segments by reducing blood pressure and cardiac contractility. ${ }^{2}$ Dihydropyridine calcium-channel blockers (CCB) is commonly used to control blood pressure in patients with TBAD. Previous studies from the International Registry of Acute Aortic Dissection indicate that dihydropyridine CCB use is associated with improved survival and reduced aortic expansion in patients with TBAD managed with medical therapy. ${ }^{3,4}$ TEVAR is a valuable option for patients with acute ( $<15$ days) and sub-acute (15 to 90 days) TBAD, which reduces mortality in

complicated TBAD and results in favourable aortic remodelling in uncomplicated TBAD compared with medical therapy. ${ }^{5-7}$ However, guidelines have not recommended the use of dihydropyridine CCB in patients with aortic disease undergoing open surgery or endovascular repair as their efficacy remains controversial. Kertai et al. ${ }^{8}$ showed that dihydropyridine CCB increased perioperative mortality in patients undergoing open repair for abdominal aortic aneurysm. In contrast, Bailey et al. ${ }^{9}$ showed that dihydropyridine $\mathrm{CCB}$ enhanced sac shrinkage after endovascular repair without increasing mortality rate. Few studies have investigated the efficacy of dihydropyridine CCB on outcomes in patients with TBAD undergoing TEVAR.

Therefore, the aim of the present study was to evaluate the effect of dihydropyridine CCB on adverse aortic events (AAE) in patients undergoing TEVAR for acute and sub-acute TBAD.

\section{Methods}

\section{Study Population}

This single-centre retrospective observational study was approved by the local Institutional Ethics Committee and the need for informed consent was waived. Between January 2010 and December 2017, 992 consecutive patients with TBAD who underwent TEVAR were retrospectively identified from the hospital database. Patients exhibiting any of the following symptoms underwent TEVAR: persistent or recurrent pain, uncontrolled hypertension despite adequate medical therapy, aortic dilation with a maximum aortic diameter $>55 \mathrm{~mm}$, malperfusion syndrome and signs of rupture including haemothorax and growing periaortic or mediastinal hematoma. Additionally, patients with risk factors such as false lumen diameter $>22 \mathrm{~mm}$, location of 
intimal tear and retrograde dissection involving the aortic arch were considered for elective TEVAR. The indications for TEVAR were described in our previous studies. ${ }^{10}$ Patients with following findings were excluded from the analyses: (a) patients with connective tissue disorders; (b) patients without hypertension [systolic blood pressure (SBP) $<140 \mathrm{mmHg}$ and diastolic blood pressure (DBP) < $90 \mathrm{mmHg}$ ], who did not fulfil the criteria for CCB prescription; ${ }^{11}$ (c) patients undergoing TEVAR for chronic TBAD (> 90 days), who experienced worse aortic remodelling and higher reintervention rate compared to those undergoing TEVAR for acute or sub-acute TBAD; ${ }^{12}$ (d) patients lost to follow-up in the first 6 months after TEVAR; (e) patients with intermittent CCB use or developing AAE within the first 3 months, because CCB duration was short and the AAE might be more related to disease condition rather than medication uses (Figure 1). Patients treated with dihydropyridine CCB without interruption within the first 3 months after TEVAR comprised the CCB group, whereas those who did not use dihydropyridine CCB after TEVAR comprised the non-CCB group.

\section{Follow-up and Outcomes}

Based on current clinical guidelines and expert opinions, all patients received treatment to ensure SBP and DBP levels of $\leq 130 / 80$ mmHg after TEVAR. ${ }^{2}, 11$ If not contraindicated, beta-blocker was recommended, combined with or without other antihypertensive drugs including dihydropyridine $\mathrm{CCB}$, angiotensin-converting enzyme inhibitor (ACEI), angiotensin receptor blocker (ARB) and alpha-blocker. ${ }^{3,13}$ However, non-dihydropyridine CCB, which was rarely combined with beta-blocker, was not administered. The patients were evaluated at 1, 3, 6 and 12 months after discharge and annually thereafter in the outpatient clinic or by telephone for blood pressure control, anti-hypertensive drug use, aorta- and non-aorta-related mortality and incidence of reintervention. Patients with unsatisfied blood pressure control had medication adjustments to meet target blood pressure as soon as possible. Data on the final types and dosages of anti-hypertensive drugs used for treatment during the study period were also collected. The patients in the CCB group who discontinued CCB and those in the non-CCB group who were prescribed CCB were censored at the time of drug switch.

The primary endpoints during follow-up were AAE, including aorta-related mortality and requirement for reintervention. Aortarelated mortality was defined as death caused directly or indirectly by TBAD or its treatment, with symptoms like chest or back pain, or evidence of aortic rupture like cardiac tamponade or new pleural effusion detected by bedside echocardiogram, and absence of any history of fatal cardiac disease. Sudden death would be considered as aorta-related death if known aortic pathologies were present. Reintervention was considered in patients with signs of aortic rupture, retrograde type $\mathrm{A}$ dissection, progressive aortic dilation caused by endoleak, distal aortic dilation (diameter $>60 \mathrm{~mm}$ or $>10 \mathrm{~mm} /$ year) and distal stent graft-induced new entry. ${ }^{2}$

\section{Data collections}

Relevant patient information, including demographic characteristics, comorbidities, imaging characteristics, operative details and medication uses, were retrospectively obtained from the medical, post-procedure, discharge and outpatient clinic notes. Demographic characteristics included age and sex. Comorbidities included hypertension, diabetes mellitus, dyslipidemia, coronary heart disease, renal dysfunction and current smoking. Hypertension was graded as follows: grade 1, SBP 140-159 $\mathrm{mmHg}$ and/or DBP 90-99 mmHg; grade $\geq 2, \mathrm{SBP} \geq 160 \mathrm{mmHg}$ and/or DBP $\geq 100 \mathrm{mmHg} .{ }^{11}$ Imaging characteristics included maximum aortic diameter of the diseased segments, false lumen status, pleural and pericardial effusion. Operative details included stage (acute or sub-acute phase), aortic stent length, use of hybrid procedure (carotid-to-carotid bypass and/or carotid-to-subclavian bypass), chimney stent and distal bare stent. Information on medication uses included the exact time of prescription and withdrawal of CCB, beta-blocker, ACEI, ARB and alpha-blocker.

\section{Statistical analysis}


Continuous variables were expressed as mean \pm standard deviation or median with interquartile range (IQR) and compared by Student's $t$-test or Mann-Whitney U-test. Categorical variables were expressed as percentage and compared by Chisquared or Fisher's exact test. To prevent the potential effect of known confounders, 1:1 propensity score matching was performed between the CCB and non-CCB groups using the nearest neighbour algorithm with a caliper width of 0.01 times. The variables included to calculate the propensity score are listed in Table 1. Differences in baseline characteristics between the 2 groups were compared using standard mean differences before and after matching, and differences of less than 10\% generally suggested minimal or no imbalance. Discrimination accuracy was validated by C-statistics of logistic regression. Matched variables were compared by Wilcoxon signed-rank test for continuous variables and McNemar's test for categorical variables. Estimates of cumulative AAE rates were calculated by the Kaplan-Meier method according to CCB use, and differences were examined with the log-rank test. Cox proportional hazards models were constructed to confirm the robustness of associations between CCB use and AAE after adjustment for other variables. We used a backward variable selection approach to select variables among confounders, and $P<0.2$ was required to remain within the multivariable model. A 2-tailed $P<0.05$ was considered statistically significant. Statistical analyses were performed using the SPSS 24.0 (IBM, Armonk, NY, USA).

\section{Results}

\section{Patients characteristics}

The study cohort comprised 548 patients, including $435(79.4 \%)$ and $113(20.6 \%)$ patients with and without postoperative CCB treatment, respectively. Among those treated with CCB, 31 (7.1\%) patients were treated with CCB only within the first year whereas the remaining 404 (92.9\%) patients were continuously treated with CCB for 1 year or longer. After matching, 101 patients in each group were considered to satisfy the conditions for final analyses (Figure 1).

Patients characteristics are shown in Table 1. Before matching, compared with the non-CCB group, the CCB group comprised higher rates of patients with grade $\geq 2$ hypertension $(79.3 \%$ vs. $55.8 \%, P<0.001)$ and those treated with multiple antihypertensive drugs (beta-blocker, $97.2 \%$ vs. $90.3 \%, P=0.003$; ARB, $57.5 \%$ vs. $35.4 \%, P<0.001$; alpha-blocker, $15.9 \%$ vs. $3.5 \%, P=$ 0.001). In addition, the rate of patients undergoing TEVAR in the acute phase was higher, whereas the rate of patients undergoing hybrid produce was lower in the CCB group compared with the non-CCB group $(71.0 \%$ vs. $58.4 \%, P=0.010 ; 22.8 \%$ vs. $37.2 \%, P=0.002$ ). After matching, there were no significant differences in demographic characteristics, comorbidities, imaging characteristics, operative details and medication uses between the CCB and non-CCB groups (standard mean difference $<10 \%$ for all). The C-statistic of the model was 0.58 , suggesting moderate predictive ability.

Table 1

Baseline characteristics 
Unmatched cohort

$(n=548)$

CCB

$(n=435)$ ort

(n=206)

$(n=113)$

Non-CCB

P SMD

$(n=101)$

$(\mathrm{n}=101)$
Demographic

characteristics

\begin{tabular}{|c|c|c|c|c|c|c|c|c|}
\hline Age (years) & $54.4 \pm 10.1$ & $55.6 \pm 11.9$ & 0.284 & 0.109 & $56.2 \pm 10.3$ & $56.2 \pm 11.4$ & 0.928 & 0.007 \\
\hline Male & 377 (86.7) & $100(88.5)$ & 0.606 & 0.055 & $90(89.1)$ & $89(88.1)$ & 0.999 & 0.031 \\
\hline \multicolumn{9}{|l|}{ Comorbidities } \\
\hline $\begin{array}{l}\text { Hypertension, } \\
\text { grade } \geq 2\end{array}$ & 345 (79.3) & $63(55.8)$ & $<0.001$ & 0.518 & $61(60.4)$ & $63(62.4)$ & 0.864 & 0.040 \\
\hline $\begin{array}{l}\text { Diabetes } \\
\text { mellitus }\end{array}$ & $33(7.6)$ & $9(8.0)$ & 0.893 & 0.014 & $7(6.9)$ & $8(7.9)$ & 0.999 & 0.038 \\
\hline Dyslipidaemia & $63(14.5)$ & 13 (11.5) & 0.414 & 0.088 & $14(13.9)$ & $13(12.9)$ & 0.999 & 0.029 \\
\hline $\begin{array}{l}\text { Coronary } \\
\text { heart disease }\end{array}$ & $61(14.0)$ & $20(17.7)$ & 0.327 & 0.100 & $20(19.8)$ & $18(17.8)$ & 0.856 & 0.050 \\
\hline $\begin{array}{l}\text { Renal } \\
\text { dysfunction }\end{array}$ & $52(12.0)$ & $10(8.8)$ & 0.353 & 0.102 & $12(11.9)$ & $10(9.9)$ & 0.815 & 0.063 \\
\hline Smoking & $202(46.4)$ & $48(42.5)$ & 0.452 & 0.080 & $46(45.5)$ & $46(45.5)$ & 0.999 & $<0.001$ \\
\hline \multicolumn{9}{|l|}{$\begin{array}{l}\text { Imaging } \\
\text { characteristics }\end{array}$} \\
\hline MAD (mm) & $38.9 \pm 8.2$ & $39.0 \pm 8.7$ & 0.910 & 0.012 & $38.6 \pm 7.5$ & $39.2 \pm 8.8$ & 0.434 & 0.076 \\
\hline $\begin{array}{l}\text { Patent false } \\
\text { lumen }\end{array}$ & $323(74.3)$ & 75 (66.4) & 0.094 & 0.173 & $65(64.4)$ & $67(66.3)$ & 0.860 & 0.041 \\
\hline $\begin{array}{l}\text { Pleural } \\
\text { effusion }\end{array}$ & 207 (47.6) & 45 (39.8) & 0.140 & 0.157 & $42(41.6)$ & $42(41.6)$ & 0.999 & $<0.001$ \\
\hline $\begin{array}{l}\text { Pericardial } \\
\text { effusion }\end{array}$ & $19(4.4)$ & $5(4.4)$ & 0.999 & 0.003 & $4(4.0)$ & $5(5.0)$ & 0.999 & 0.048 \\
\hline \multicolumn{9}{|l|}{$\begin{array}{l}\text { Operative } \\
\text { details }\end{array}$} \\
\hline Acute TBAD & 309 (71.0) & $66(58.4)$ & 0.010 & 0.266 & $61(60.4)$ & $59(58.4)$ & 0.864 & 0.020 \\
\hline $\begin{array}{l}\text { Stent length } \\
(\mathrm{mm})\end{array}$ & $\begin{array}{l}185.0(185.0- \\
200.0)\end{array}$ & $\begin{array}{l}200.0(185.0- \\
205.0)\end{array}$ & 0.150 & 0.185 & $\begin{array}{l}200.0(185.0- \\
205.0)\end{array}$ & $\begin{array}{l}200.0(185.0- \\
205.0)\end{array}$ & 0.735 & 0.049 \\
\hline $\begin{array}{l}\text { Hybrid } \\
\text { procedure }\end{array}$ & 99 (22.8) & $42(37.2)$ & 0.002 & 0.318 & 34 (33.7) & $35(34.7)$ & 0.999 & 0.021 \\
\hline $\begin{array}{l}\text { Chimney } \\
\text { stent }\end{array}$ & $72(16.6)$ & $21(18.6)$ & 0.608 & 0.053 & 20 (19.8) & $18(17.8)$ & 0.860 & 0.050 \\
\hline $\begin{array}{l}\text { Distal bare } \\
\text { stent }\end{array}$ & $25(5.7)$ & $8(7.1)$ & 0.596 & 0.054 & $5(5.0)$ & $5(5.0)$ & 0.999 & $<0.001$ \\
\hline \multicolumn{9}{|l|}{$\begin{array}{l}\text { Medication } \\
\text { uses }\end{array}$} \\
\hline Beta-blocker & 423 (97.2) & $102(90.3)$ & 0.003 & 0.290 & $96(95.0)$ & $95(94.1)$ & 0.999 & 0.043 \\
\hline ACEI & $40(9.2)$ & $6(5.3)$ & 0.184 & 0.150 & $7(6.9)$ & $6(5.9)$ & 0.999 & 0.040 \\
\hline
\end{tabular}




$\begin{array}{lllllllll}\text { ARB } & 250(57.5) & 40(35.4) & <0.001 & 0.453 & 38(37.6) & 40(39.6) & 0.860 & 0.040 \\ \text { Alpha-blocker } & 69(15.9) & 4(3.5) & 0.001 & 0.425 & 3(3.0) & 4(4.0) & 0.999 & 0.054\end{array}$

Values are mean \pm standard deviation, median (interquartile range) or $\mathrm{n}(\%)$.

$A C E l$, angiotensin-converting enzyme inhibitor; $A R B$, angiotensin receptor blocker; $C C B$, calcium-channel blocker; MAD, maximum aortic diameter; SMD, standard mean difference; TBAD, type B aortic dissection.

\section{Overall outcomes}

Outcomes of the study patients are shown in Table 2. In the unmatched cohort, the median follow-up period was 35.3 (IQR, 16.9-60.0) months and 31.8 (IQR, 16.7-60.0) months in the CCB and non-CCB groups, respectively $(P=0.447)$. AAE occurred in $52(12.0 \%)$ and $29(25.7 \%)$ patients in the CCB and non-CCB groups, respectively $(P<0.001)$. A total of 23 patients $(4.2 \%)$ aorta-related mortality, including 9 cases $(1.6 \%)$ of sudden death. Additionally, non-aorta-related mortality occurred in 14 (3.2\%) and $3(2.7 \%)$ patients in the CCB and non-CCB groups, respectively $(P=0.999)$. All patients reached target blood pressure at 3 months after TEVAE, and there were no differences in SBP and DBP between the CCB and non-CCB groups.

\section{Table 2}

Outcomes 


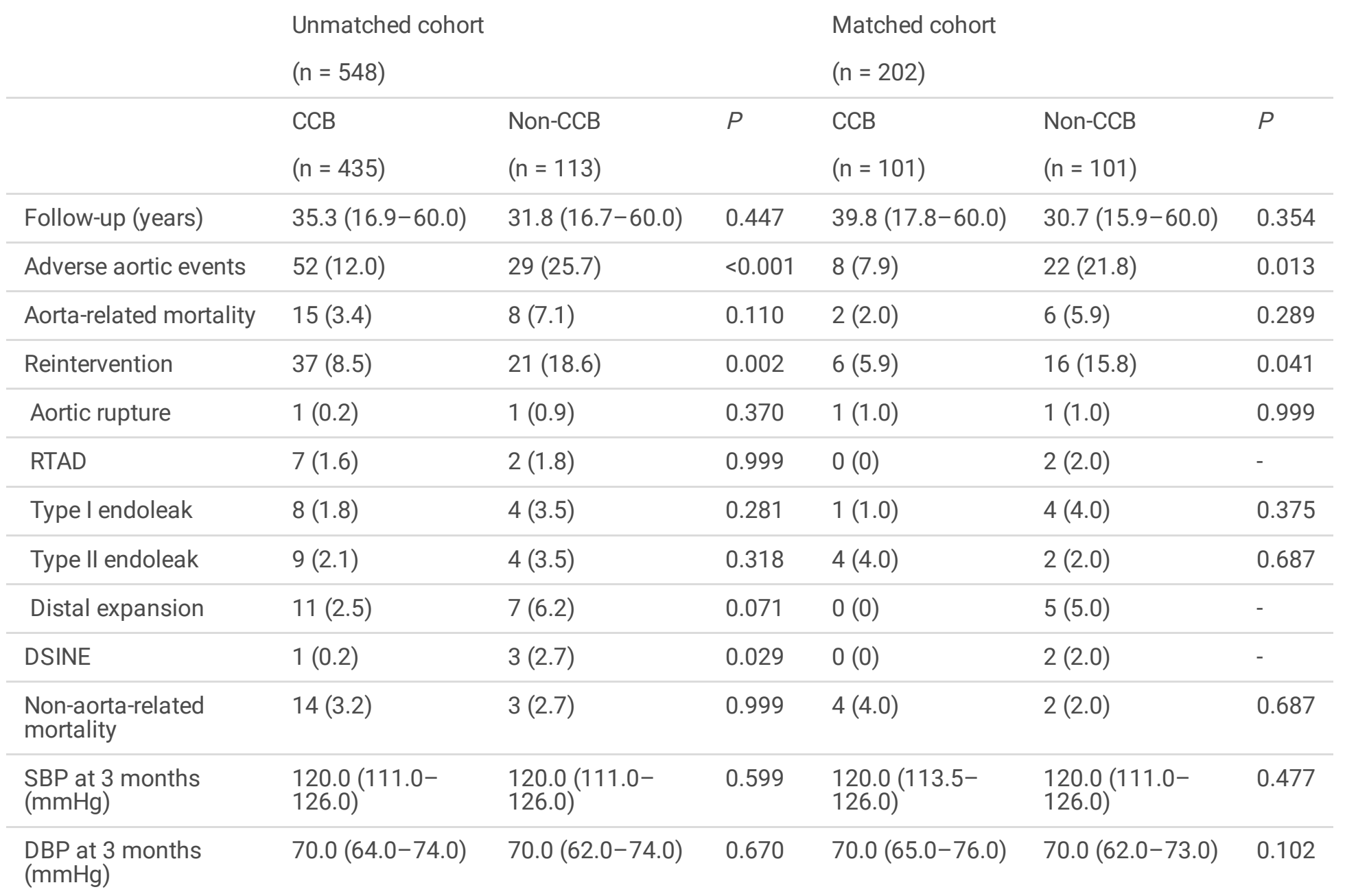

Values are median (interquartile range) or $\mathrm{n}(\%)$.

CCB, calcium-channel blocker; DBP, diastolic blood pressure; DSINE, distal stent graft-induced new entry; RTAD, retrograde type A dissection; SBP, systolic blood pressure.

Types and daily dosages of CCB are shown in Figure 2. The most common type of CCB was amlodipine (84.1\%), followed by nifedipine (11.7\%) and felodipine (4.1\%). The AAE rate was not different between the patients treated with amlodipine (12.3\%) and those treated with nifedipine $(9.8 \%, P=0.608)$ or felodipine $(11.1 \%, P=0.999)$. Furthermore, there was no difference in the AAE rate between the patients treated with 5 and $10 \mathrm{mg} /$ day amlodipine $(15.7 \% \mathrm{vs} .10 .6 \%, P=0.161)$, between those treated with 30 and $60 \mathrm{mg} /$ day nifedipine (9.7\% vs. $10.0 \%, P=0.999)$ and between those treated with 5 and $10 \mathrm{mg} /$ day felodipine (0 vs. $18.2 \%, P=0.497)$.

In the unmatched cohort, the AAE incidence rates at 1, 3 and 5 years in the CCB group were 4.1, 3.7 and 3.3 per 1000 patients per year, respectively; those in the non-CCB group were 8.7, 6.3 and 7.3 per 1000 patients per year, respectively. The mean time to AAE were 54.1 [95\% confidence interval (Cl) 52.5-55.6] months and 50.0 (95\% $\mathrm{Cl} 46.1-53.4)$ months in the CCB and nonCCB groups, respectively. Log-rank test analysis revealed that the levels of freedom from AAE were significantly different between the 2 groups $(P<0.001$; Figure $3 \mathrm{~A})$.

\section{Propensity score matching analysis and outcomes}

In the matched cohort, the median follow-up period was 39.8 (IQR, 17.8-60.0) months and 30.7 (IQR, 15.9-60.0) months in the CCB and non-CCB groups, respectively $(P=0.354)$. AAE occurred in $8(7.9 \%)$ and $22(21.8 \%)$ patients in the CCB and non-CCB groups, respectively ( $P=0.013$; Table 2$)$. 
The AAE incidence rates at 1, 3 and 5 years in the CCB group were 4.4, 2.6 and 2.1 per 1000 patients per year, respectively; those in the non-CCB group were 8.9, 6.1 and 6.3 per 1000 patients per year, respectively. The mean time to AAE were 55.8 ( $95 \%$ $\mathrm{Cl} 53.0$-58.6) months and $50.4(95 \% \mathrm{Cl} 46.6-54.3)$ months in the $\mathrm{CCB}$ and non-CCB groups, respectively. Log-rank test analysis revealed that the levels of freedom from AAE were significantly different between the 2 groups $(P=0.007$; Figure 3B).

\section{Multivariable analysis}

The results of univariable and multivariable analyses are shown in Table 3. In the unmatched cohort, CCB use [hazard ratio (HR) $0.50,95 \% \mathrm{Cl} 0.32-0.80 ; P=0.003$ ] was associated with a significantly lower AAE rate after adjustment for other risk factors. However, beta-blocker, ACEI, ARB and alpha-blocker did not show significant associations with a lower AAE rate. Furthermore, for each 1-mm increase in maximum aortic diameter, the AAE rate increased 1.04 times $(95 \% \mathrm{Cl} 1.02-1.06 ; P<$ 0.001). Hybrid procedure (HR 2.41, 95\% Cl 1.54-3.77; $P<0.001$ ) was also an independent risk factor for AAE. In the matched cohort, the association between CCB use and AAE rate was minimally changed (HR $0.34,95 \% \mathrm{Cl} 0.15-0.75 ; P=0.008)$.

\section{Table 3}

Univariable and multivariable predictors of adverse aortic events 
CCB

\begin{tabular}{llll}
$\mathrm{HR}(95 \% \mathrm{Cl})$ & $P$ & $\mathrm{HR}(95 \% \mathrm{Cl})$ & $P$ \\
\hline $0.45(0.29-0.71)$ & 0.001 & $\begin{array}{l}0.50(0.32- \\
0.80)\end{array}$ & 0.003
\end{tabular}
HR $(95 \% \mathrm{Cl}) \quad P$ $0.34(0.15-\quad 0.008$ $0.75)$

Demographic characteristics

Age (for each 1-year increase)

$\begin{array}{lll}1.01(0.99-1.03) & 0.494 & - \\ 1.20(0.58-2.49) & 0.627 & -\end{array}$

Male

$1.20(0.58-2.49)$

Comorbidities

Hypertension, Grade $\geq 2$

0.98
$1.62)$$\quad(0.60-\quad 0.949 \quad-$

Diabetes

$0.76(0.31-1.87) \quad 0.543$

Dyslipidaemia

$1.16(0.63-2.14) \quad 0.637$

\section{Coronary heart disease}

$1.03(0.56-1.91)$

0.917

Renal dysfunction

$0.68(0.30-1.56)$

0.362

Smoking

$0.70(0.45-1.10)$

0.119

Imaging characteristics

MAD (for each 1-mm increase)

\begin{tabular}{ll}
$1.04(1.02-1.06)$ & 0.001 \\
\hline $1.09(0.66-1.78)$ & 0.747 \\
\hline $1.02(0.66-1.58)$ & 0.938 \\
$1.13(0.41-3.08)$ & 0.813 \\
\hline
\end{tabular}

\section{Patent false lumen}

Pleural effusion

Pericardial effusion

Operative details

Acute TBAD
Stent length (for each 1-mm
increase)

Hybrid procedure

Chimney stent

Distal bare stent

Medication uses

\begin{tabular}{llll} 
Beta-blocker & $0.97(0.31-3.08)$ & 0.960 & - \\
ACEI & $0.84(0.37-1.93)$ & 0.678 & - \\
\hline ARB & $0.93(0.60-1.43)$ & 0.736 & - \\
\hline Alpha-blocker & $1.31(0.72-2.37)$ & 0.372 & -
\end{tabular}

ACEl, angiotensin-converting enzyme inhibitor; $\mathrm{ARB}$, angiotensin receptor blocker; $\mathrm{CCB}$, calcium-channel blocker; $\mathrm{Cl}$, confidence interval; HR, hazard ratio; MAD, maximum aortic diameter. 


\section{Discussion}

In the present study evaluating the effect of CCB on outcomes in patients undergoing TEVAR for acute and sub-acute TBAD, CCB use was associated with a significantly lower AAE rate in both the matched cohort analysis and multivariable analyses, regardless of types and dosages of CCB.

TEVAR, a valuable option for patients with TBAD, is associated with a high AAE rate during follow-up even after successful operation. Corsini et al. ${ }^{14}$ reported that the reintervention rate after TEVAR was $35.9 \%$ in patients with type $B$ acute aortic syndrome after TEVAR. In the present study, $18.6 \%$ of the patients experienced AAE during follow-up. The patients with a larger aortic diameter and those who underwent a hybrid produce were at higher risk for $A A E$, consistent with previous studies. ${ }^{15,16}$ Therefore, postoperative management of patients undergoing TEVAR remains a challenge. The primary goal after TBAD include optimal blood pressure control to promote aortic stability and to prevent aortic expansion. In the present study, 79.4\% of the patients with TBAD after TEVAR received CCB treatment. Several studies reported the effects of CCB in patients with TBAD managed with medical therapy. Jonker et al. ${ }^{4}$ reported that CCB could reduce the rate of aortic expansion in patients with TBAD. Similarly, Suzuki et al. ${ }^{3}$ reported that the use of CCB and beta-blocker improved survival in patients with TBAD who were managed with medical therapy, while the use of ACEl did not reduce mortality. However, beta-blocker failed to improve event-free survival rate in the present study. This discordance might be due to the high proportion of beta-blocker use in both the CCB and non-CCB groups ( $97.2 \%$ and $90.3 \%$, respectively). Moreover, in the present study, age showed no association with $\mathrm{AAE}$, inconsistent with previous studies. ${ }^{14}$ The discordance might be explained by the shorter follow-up period in this cohort.

Data on CCB use are lacking in patients who underwent TEVAR and surgery for aortic disease. In the present study, postoperative CCB use after TEVAR in patients with TBAD was associated with a significantly lower AAE rate independently of demographic characteristics, comorbidities, imaging characteristics, operative details and use of other medications. Liu et al. ${ }^{17}$ reported that CCB treatment was a protective factor for late mortality in the cohort which did not distinguish patients managed with medical therapy and those undergoing TEVAR. Similarly, Bailey et al. ${ }^{9}$ reported that CCB might enhance sac shrinkage in patients with aortic aneurysm after endovascular repair. Nevertheless, in patients undergoing acute or elective aortic aneurysm surgery, perioperative use of dihydropyridine CCB was associated with higher risk of mortality, mainly due to cardiac complications, which could be neutralised by beta-blocker use. ${ }^{8}$ This effect could be explained by high frequency tachycardia and prolonged myocardial ischaemia induced by dihydropyridine CCB. In the present study, there was no difference in nonaorta-related mortality between the CCB and non-CCB groups, which might be attributable to less damage associated with TEVAR compared with open surgery.

Although both oral and intravenous CCBs can effectively and safely lower high blood pressure in patients with TBAD, the mechanism underlying the protective effect of $C C B$ against $A A E$ in patients with TBAD is not completely clear. ${ }^{1,18}$ Blood pressure stabilisation can only partially explain the protective effect of $C C B$, since other anti-hypertensive drugs such as ACEI, ARB and alpha-blocker are not significantly associated with lower AAE. We hypothesise that CCB may have additional beneficial effects on the diseased aorta. Although TBAD and aortic aneurysm are distinct conditions, they share several pathological features such as leukocytic infiltration and extracellular matrix remodelling. ${ }^{19,20}$ Previous studies have shown that the dihydropyridine CCB amlodipine ameliorated angiotensin II-induced vascular pathologies such as oxidative stress, increased matrix metalloproteinases activity, nitric oxide synthesis and leukocyte migration, therefore reducing the formation of abdominal and thoracic aortic aneurysms. ${ }^{21-24}$ In addition, other CCB such as nifedipine and azelnidipine were shown to reduce experimental abdominal aortic aneurysm. ${ }^{25,26}$ TEVAR could trigger the secretion of tumour necrosis factor-a, resulting in an inflammatory environment, whereas nifedipine inhibits tumour necrosis factor-a-induced endothelial cell apoptosis and reactive oxygen species generation; therefore, CCB might attenuate post-TEVAR inflammation. ${ }^{27,} 28$

\section{Limitations}


This study had several limitations. First, inherent selection bias was inevitable in this retrospective study. Although data from multicentre randomised trials suggestted that losartan could reduce aortic root dilation rate in patients with Marfan syndrome, no data existed on the use of ACEI or ARB in chronic TBAD. ${ }^{29}$ Current clinical guideline have not recommended ACEI, ARB or CCB as a priority. ${ }^{2}$ The selection of anti-hypertension drugs was non-random and based on the comorbidities of patient and discretion of treating physicians. For example, the patients with diabetes mellitus are treated with ACEI or ARB, whereas those with renal dysfunction might be considered for treatment with CCB or alpha-blocker as an alternative. Despite the propensity score matching, residual confounding might have occurred because of unknown confounders. Second, it was inevitable to reduce the sample size after matching. Third, the low event rate, especially mortality rate might be attributed to the censoring of the study patients because of drug switch. Forth, the overall study population was quite young and some patients with connective tissue disorder may be missing because of insignificant symptoms. Finally, the patients managed with medical therapy alone in our institution were not included in this study due to the lack of complete follow-up data.

\section{Conclusion}

Postoperative use of dihydropyridine $\mathrm{CCB}$ has a protective effect, with reduced AAE rate observed in patients treated with $\mathrm{CCB}$ after TEVAR for acute and sub-acute TBAD. Stringent medication surveillance is recommended during follow-up. Further prospective and comprehensive studies are warranted to optimise medical therapy in these patients.

\section{Abbreviations}

AAE, adverse aortic events

ACEl, angiotensin-converting enzyme inhibitor

ARB, angiotensin receptor blocker

CCB, calcium-channel blocker

$\mathrm{Cl}$, confidence interval

DBP, diastolic blood pressure

HR, hazard ratio

MAD, maximum aortic diameter

SMD, standard mean difference

SBP, systolic blood pressure

TBAD, type $B$ aortic dissection

TEVAR, thoracic endovascular aortic repair

\section{Declarations}

\section{Acknowledgement}

None. 


\section{Author contributions}

F.Y., Q.G. and J.L. were involved in the conception and the design of the study. F.Y. and L.C. collected, analyzed the data and wrote the paper. L.C. and J.L. performed the statistical work. C.H., W.M., E.X. and X.Y. contributed to collect the data. S.L. and H.Z. contributed to critical revision of the manuscript for important intellectual content. All authors reviewed the manuscript and agreed with the final version.

\section{Funding}

This work was supported by grants from Guangdong Provincial Key Laboratory of Coronary Artery Disease Prevention Fund (grant NO. Y022017018) and High-level Hospital Construction Project (grant NO. DFJH201807 and NO. DFJH201811).

\section{Availability of data and materials}

The datasets used and/or analyzed during the current study are de-identified and available from the corresponding author on reasonable request.

\section{Ethics approval and consent to participate}

This study was performed in accordance with the Declaration of Helsinki and approved by the ethics committee of the Guangdong Provincial People's Hospital (\#201807) and the need for informed consent was waived because of the retrospective nature of the analysis.

\section{Consent for publication}

Not applicable.

\section{Competing interests}

The authors declare that there is no conflict of interest.

\section{Author details}

1 Department of Emergency and Critical Care Medicine, Guangdong Provincial People's Hospital, Guangdong Academy of Medical Sciences, Guangzhou, China

2 Department of Cardiology, Guangdong Cardiovascular Institute, Guangdong Provincial People's Hospital, Guangdong Academy of Medical Sciences, Guangzhou, China

\section{References}

1. Evangelista A, Isselbacher EM, Bossone E, Gleason TG, Eusanio MD, Sechtem U, et al. Insights from the International Registry of Acute Aortic Dissection: a 20-Year experience of collaborative clinical research.

Circulation. 2018; 137 (17):1846-60. 
2. Erbel R, Aboyans V, Boileau C, Bossone E, Bartolomeo RD, Eggebrecht H, et al. 2014 ESC Guidelines on the diagnosis and treatment of aortic diseases: document covering acute and chronic aortic diseases of the thoracic and abdominal aorta of the adult. The Task Force for the Diagnosis and Treatment of Aortic Diseases of the European Society of Cardiology (ESC). Eur Heart J. 2014; 35 (41):2873-926.

3. Suzuki T, Isselbacher EM, Nienaber CA, Pyeritz RE, Eagle KA, Tsai TT, et al. Type-selective benefits of medications in treatment of acute aortic dissection (from the International Registry of Acute Aortic Dissection [IRAD]). Am J Cardiol. 2012; 109 (1):122-7.

4. Jonker FH, Trimarchi S, Rampoldi V, Patel HJ, O'Gara P, Peterson MD, et al. Aortic expansion after acute type B aortic dissection. Ann Thorac Surg. 2012; 94 (4):1223-9.

5. Fattori R, Montgomery D, Lovato L, Kische S, Di Eusanio M, Ince H, et al. Survival after endovascular therapy in patients with type $B$ aortic dissection: a report from the International Registry of Acute Aortic Dissection (IRAD). JACC CardiovasC Interv. 2013; 6 (8):876-82.

6. Brunkwall J, Kasprzak P, Verhoeven E, Heijmen R, Taylor P, Alric P, et al. Endovascular repair of acute uncomplicated aortic type B dissection promotes aortic remodelling: 1 year results of the ADSORB trial. Eur $J$ Vasc Endovasc Surg. 2014; 48 (3):285-91.

7. Nienaber CA, Kische S, Rousseau H, Eggebrecht H, Rehders TC, Kundt G, et al. Endovascular repair of type B aortic dissection: long-term results of the randomized investigation of stent grafts in aortic dissection trial. Circ Cardiovasc Interv. 2013; 6 (4):407-16.

8. Kertai MD, Westerhout CM, Varga KS, Acsady G, Gal J. Dihydropiridine calcium-channel blockers and perioperative mortality in aortic aneurysm surgery. Br J Anaesth. 2008; 101 (4):458-65.

9. Bailey MA, Sohrabi S, Flood K, Griffin KJ, Rashid ST, Johnson AB, et al. Calcium channel blockers enhance sac shrinkage after endovascular aneurysm repair. J Vasc Surg. 2012; 55 (6):1593-9.

10. Zhu Y, Luo S, Ding H, Liu Y, Huang W, Xie N, et al. Predictors associated with an increased prevalence of postimplantation syndrome after thoracic endovascular aortic repair for type B aortic dissection. Eur J Cardiothorac Surg. 2019; 55 (5):9981005.

11. Williams B, Mancia G, Spiering W, Agabiti Rosei E, Azizi M, Burnier M, et al. 2018 ESC/ESH Guidelines for the management of arterial hypertension. Eur Heart J. 2018; 39 (33):3021-104.

12. VIRTUE Registry Investigators. Mid-term outcomes and aortic remodelling after thoracic endovascular repair for acute, subacute, and chronic aortic dissection: the VIRTUE Registry. Eur J Vasc Endovasc Surg. 2014; 48 (4):363-71.

13. Genoni M, Paul M, Jenni R, Graves K, Seifert B, Turina M. Chronic beta-blocker therapy improves outcome and reduces treatment costs in chronic type B aortic dissection. Eur J Cardiothorac Surg. 2001; 19 (5):606-10.

14. Corsini A, Pacini D, Lovato L, Russo V, Lorenzini M, Foà A, et al. Long-term Follow up of Patients with Acute Aortic Syndromes: Relevance of both Aortic and Non-aortic Events. Eur J Vasc Endovasc Surg. 2018; 56 (2):200-08.

15. Spinelli D, Benedetto F, Donato R, Piffaretti G, Marrocco-Trischitta MM, Patel HJ, et al. Current evidence in predictors of aortic growth and events in acute type B aortic dissection. J Vasc Surg. 2018; 68 (6):1925-35.e8.

16. Benrashid E, Wang H, Keenan JE, Andersen ND, Meza JM, McCann RL, et al. Evolving practice pattern changes and outcomes in the era of hybrid aortic arch repair. J Vasc Surg. 2016; 63 (2):323-31.

17. Liu YJ, Wang XZ, Wang Y, He RX, Yang L, Jing QM, et al. Correlation between sex and prognosis of acute aortic dissection in the Chinese population. Chin Med J (Engl). 2018; 131 (12):1430-35.

18. Alviar CL, Gutierrez A, Cho L, Krishnaswamy A, Saleh A, Lincoff MA, et al. Clevidipine as a therapeutic and cost-effective alternative to sodium nitroprusside in patients with acute aortic syndromes. Eur Heart $J$ Acute Cardiovasc Care. 2020; 9 (3_suppl):S5-12.

19. He R, Guo DC, Estrera AL, Safi HJ, Huynh TT, Yin Z, et al. Characterization of the inflammatory and apoptotic cells in the aortas of patients with ascending thoracic aortic aneurysms and dissections. $J$ Thorac Cardiovasc

Surg. 2006; 131 (3):671-8.

Page 13/17 
20. Kuivaniemi $\mathrm{H}$, Platsoucas $\mathrm{CD}$, Tilson MD 3rd. Aortic aneurysms: an immune disease with a strong genetic component. Circulation. 2008; 117 (2):242-52.

21. Yoshii T, Iwai M, Li Z, Chen R, Ide A, Fukunaga S, et al. Regression of atherosclerosis by amlodipine via anti-inflammatory and anti-oxidative stress actions. Hypertens Res. 2006 (6); 29:457-66.

22. Yue $H$, Uzui $H$, Shimizu $H$, Nakano A, Mitsuke $Y$, Ueda T, et al. Different effects of calcium channel blockers on matrix metalloproteinase-2 expression in cultured rat cardiac fibroblasts. J Cardiovasc Pharmacol. 2004; 44 (2):223-30.

23. Kataoka C, Egashira K, Ishibashi M, Inoue S, Ni W, Hiasa K, et al. Novel anti-inflammatory actions of amlodipine in a rat model of arteriosclerosis induced by long-term inhibition of nitric oxide synthesis. Am J Physiol Heart Circ Physiol. 2004; 286:H768-74.

24. Das R, Burke T, Van Wagoner DR, Plow EF. L-type calcium channel blockers exert an antiinflammatory effect by suppressing expression of plasminogen receptors on macrophages. Circ Res. 2009 (2); 105:167-75.

25. Tomita N, Yamasaki K, Izawa K, Kunugiza Y, Osako MK, Ogihara T, et al. Inhibition of experimental abdominal aortic aneurysm progression by nifedipine. Int J Mol Med. 2008; 21 (2):239-44.

26. Yokokura H, Hiromatsu S, Akashi H, Kato S, Aoyagi S. Effects of calcium channel blocker azelnidipine on experimental abdominal aortic aneurysms. Surg Today. 2007; 37 (6):468-73.

27. Rowlands TE, Homer-Vanniasinkam S. Paradoxical neutrophil elastase release in endovascular abdominal aortic aneurysm repair. Vasc Endovascular Surg. (2007) 41 (1):48-54.

28. Yamagishi S, Inagaki Y, Kikuchi S. Nifedipine inhibits tumor necrosis factor-alpha-induced monocyte chemoattractant protein-1 overexpression by blocking NADPH oxidase-mediated reactive oxygen species generation. Drugs Exp Clin Res. 2003; 29 (4):147-52.

29. Groenink M, den Hartog AW, Franken R, Radonic T, de Waard V, Timmermans J, et al. Losartan reduces aortic dilatation rate in adults with Marfan syndrome: a randomized controlled trial. Eur Heart J. 2013; 34 (45):3491-500.

\section{Figures}




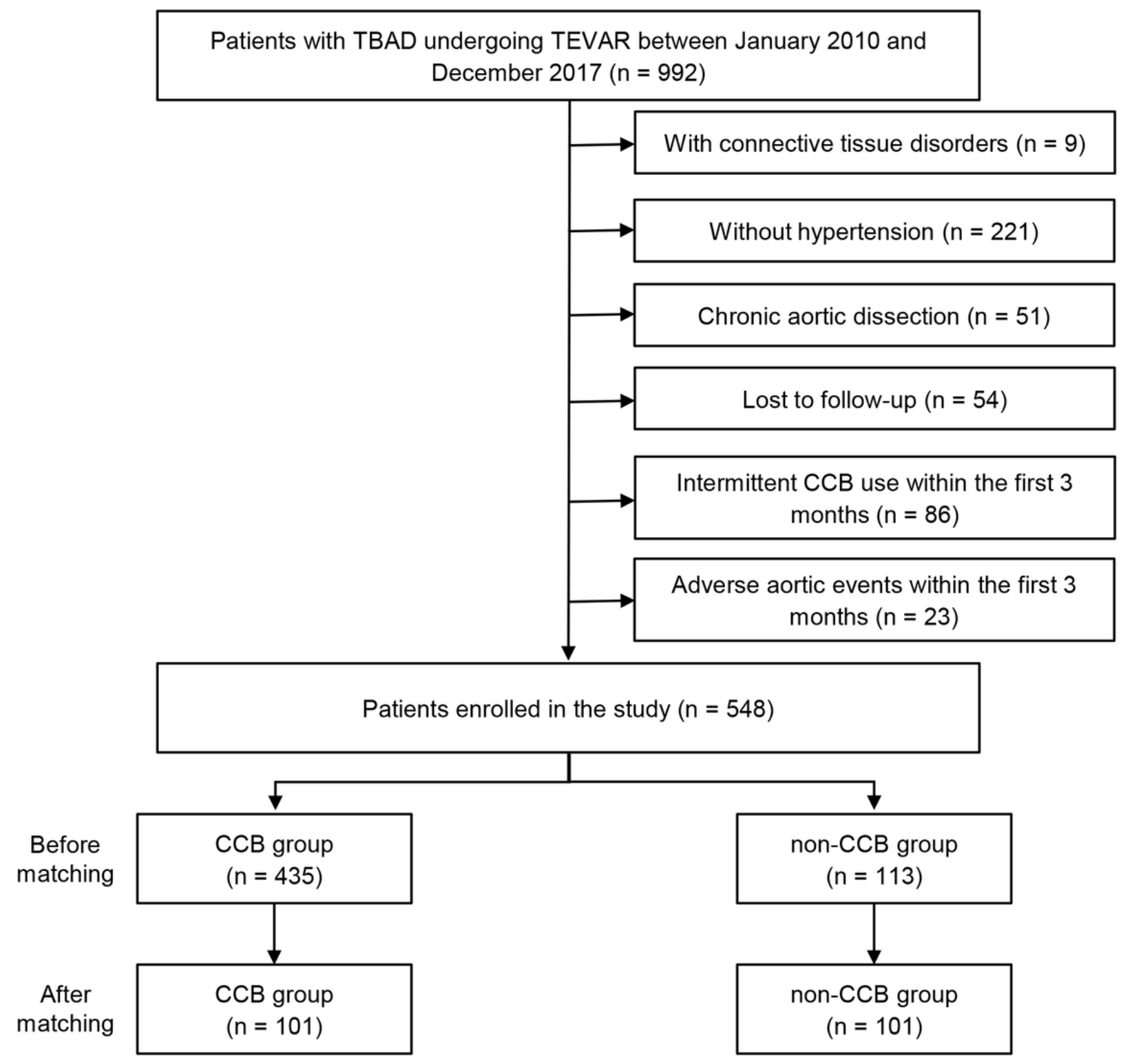

Figure 1

Flow chart for patient selection. CCB, calcium-channel blocker; TEVAR, thoracic endovascular aortic repair. 


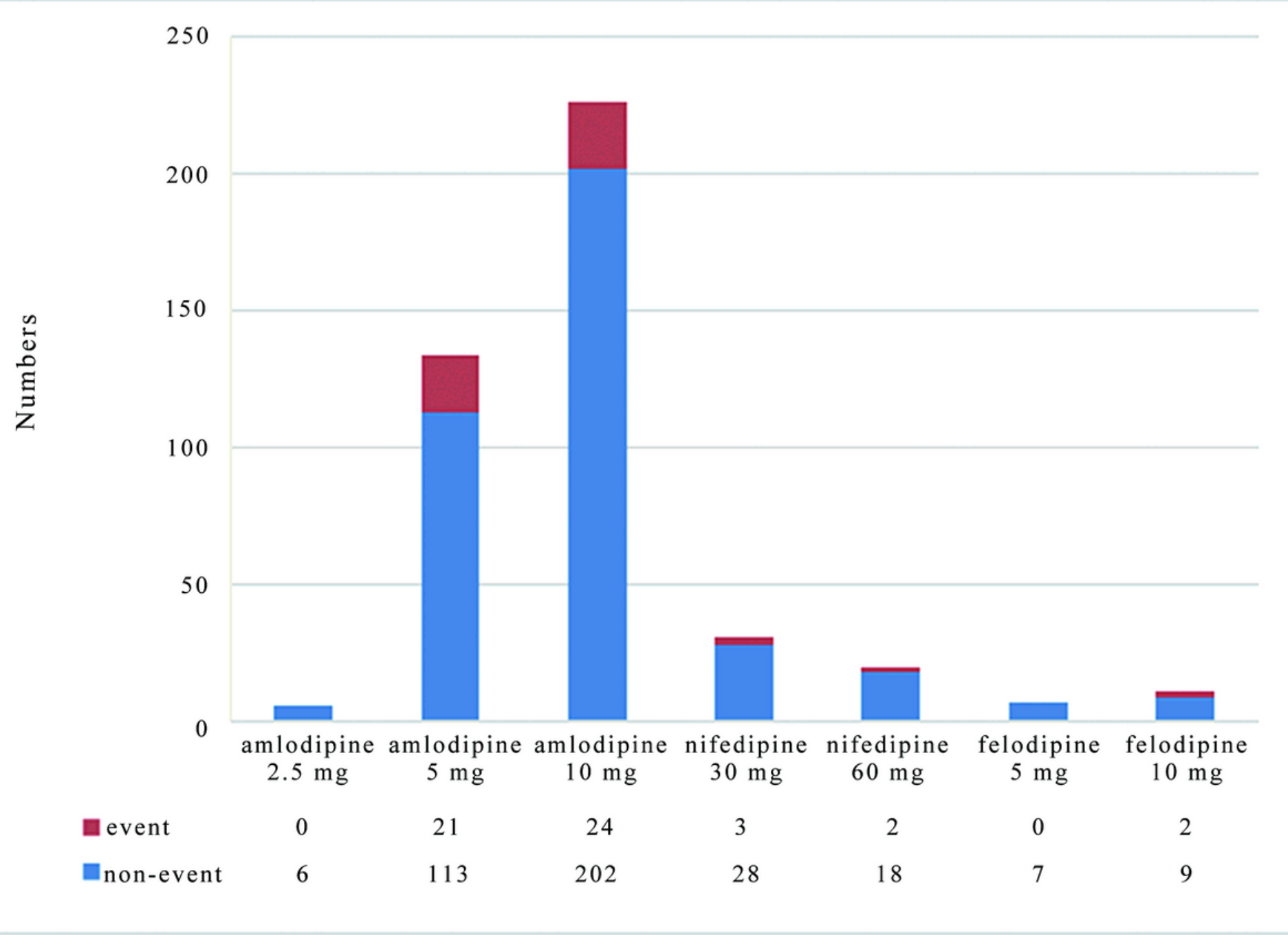

\section{Figure 2}

Types and daily dosages of calcium-channel blockers.

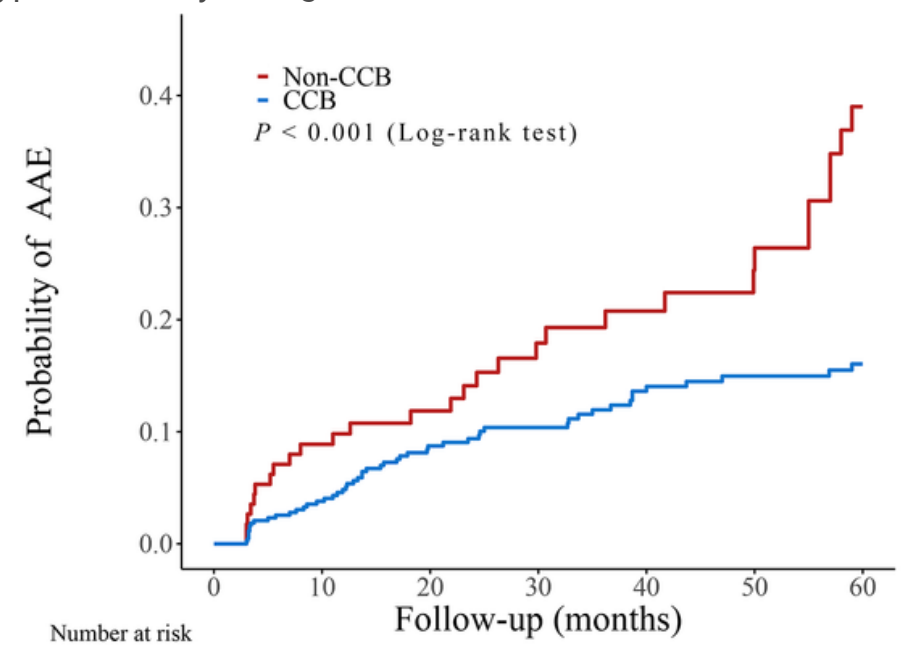

$\begin{array}{cccccccc}\text { Non-CCB } & 113 & 99 & 79 & 60 & 49 & 38 & 29 \\ \text { SE } & - & 0.03 & 0.03 & 0.04 & 0.04 & 0.05 & 0.06 \\ \text { CCB } & 435 & 375 & 297 & 241 & 205 & 172 & 151 \\ \text { SE } & - & 0.01 & 0.01 & 0.02 & 0.02 & 0.02 & 0.02\end{array}$

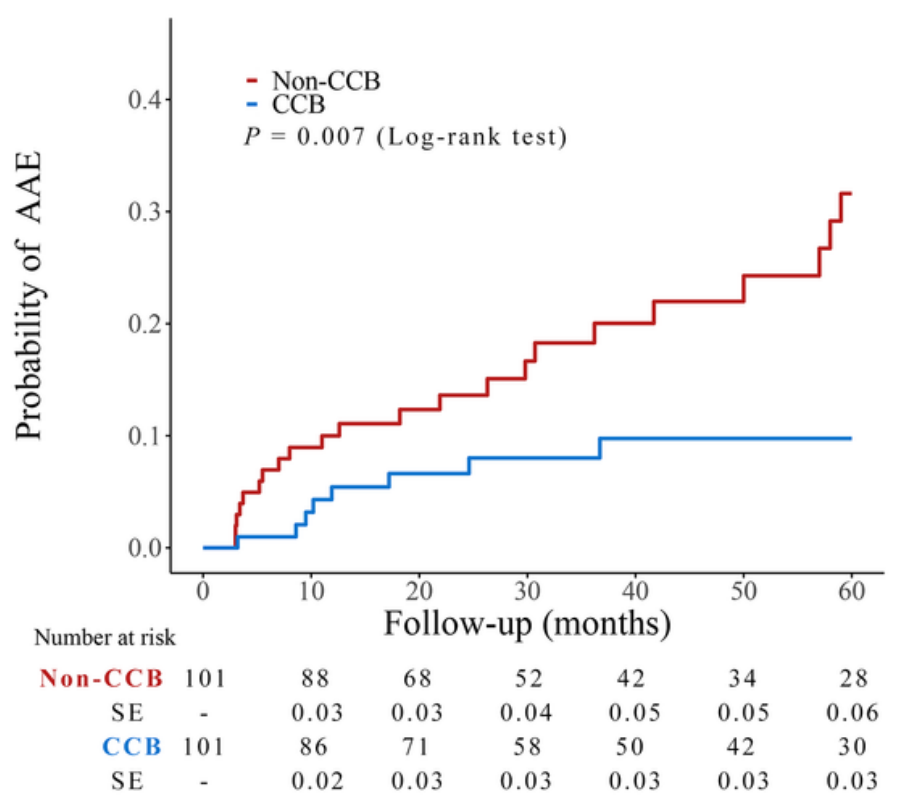




\section{Figure 3}

Kaplan-Meier curves of adverse aortic events according to CCB use in both the unmatched (A) and matched (B) cohorts. CCB, calcium-channel blocker. 